\title{
Influence of Copper Particles on Breakdown Voltage and Frequency-Dependent Dielectric Property of Vegetable Insulating Oil
}

\author{
Jing Zhang ${ }^{1}$, Feipeng Wang ${ }^{1, *}$, Jian $\mathrm{Li}^{1, *}$, Hehuan Ran ${ }^{1}$ and Dali Huang ${ }^{2}$ \\ 1 State Key Laboratory of Power Transmission Equipment \& System Security and New Technology, School of \\ Electrical Engineering, Chongqing University, Chongqing 400044, China; zhangjing2012@cqu.edu.cn (J.Z.); \\ ranhehuan@cqu.edu.cn (H.R.) \\ 2 Guangzhou Power Supply Co. Ltd., Guangzhou 510000, China; huangdali@cqu.edu.cn \\ * Correspondence: fpwang@cqu.edu.cn (F.W.); lijian@cqu.edu.cn (J.L.); Tel.: +86-23-6510-2437 (F.W. \& J.L.)
}

Academic Editor: Issouf Fofana

Received: 26 May 2017; Accepted: 4 July 2017; Published: 6 July 2017

\begin{abstract}
The insulating performance of oil is vulnerable to particles especially the conductive particles. This paper investigated the influence of copper particles of micrometer size on the breakdown strength and frequency-dependent properties of vegetable oil. The AC breakdown voltage of contaminated vegetable oil with copper particles of different numbers (ranging from $10^{3}$ to $10^{6}$ ) was measured. The frequency-dependent dielectric properties including volume resistivity, relative permittivity and dissipation factor of the contaminated vegetable oil with copper particles of various volumetric concentrations $(0.011 \%, 0.056 \%$ and $0.112 \%)$ were measured. Identical experiments were conducted with mineral oil for comparison. Results show that the AC breakdown voltage of vegetable oil decreases with the increase of copper particle concentration. The mineral oil exhibits a similar trend, but the influence of copper particles on the AC breakdown voltage of vegetable oil is less significant than that on mineral oil because of its greater viscosity. The relative permittivity and dissipation factor increase with increasing copper volumetric concentration while the volume resistivity decreases. The influence of copper particles on them is significant at low frequencies and this influence becomes inconspicuous as the frequency increases. Similar results were observed for mineral oil.
\end{abstract}

Keywords: vegetable insulating oil; breakdown voltage; volume resistivity; relative permittivity; dissipation factor; copper particles

\section{Introduction}

Power transformers are the key components of the power system and insulating oil plays a major role in power transformers, acting as insulation and coolant [1]. Vegetable insulating oil has been used successfully in distribution transformers in certain countries and regions, and they are under research and development for application in large power transformers [2-4]. As a new and environment-friendly substitute of mineral insulating oil, it has good dielectric properties. Its high permittivity is conducive to improving electric field distribution in oil-paper insulation structure. Vegetable insulating oil has greater hydrophilicity than mineral insulating oil as hydrogen bonds exist in molecules of natural esters, which contributes to extending the remaining life of paper insulation in transformer [5].

Particles are typical pollutants that affect insulating performance of insulating oil. CIGRE working group WG 12.17 presented a significant number of high-voltage transformer failures attributed to particles [6]. The particles in insulating oil are mainly metallic particles including copper, iron and 
aluminum particles, and nonmetallic particles like carbon, cellulose fibre and dust [6,7]. Their diameter mainly lies in the range of 10-100 $\mu \mathrm{m}$, with few particles greater than $100 \mu \mathrm{m}$. Those particles are usually introduced during the manufacturing and installation process of transformers before energization, and the insulation (paper and oil) degradation, internal discharge and abrasion and friction of mechanical components in transformers during operation [6].

A lot of research work was carried out dealing with the influence of particles on the dielectric properties of insulating oil. For breakdown strength of transformer oil, the voltages applied are mainly AC voltage [8-11], DC voltage [12] and impulse voltage [13], and some publications took into account the combined effect of water or temperature [8-10,13-20]. The influence of particles on the breakdown strength of oil differs as the particle size varies. Publication [21-23] reported that the addition of nanoparticles to oil improves the breakdown voltage by about 20 percent. Nevertheless, it is reported that the addition of conductive particles like copper particles of micrometer size significantly reduces the breakdown voltage [9]. M. Krins et al. reported that the breakdown voltage of carbonized oil reduces by more than 20 percent at about $20^{\circ} \mathrm{C}$ because of the agglomeration of carbon particles [15]. More results show that conducting particles affect the dielectric strengths much more than insulating particles, and larger particles reduce the breakdown voltage even more significantly [24,25]. The particles in insulating oil suspends and flow with the oil. They will move constantly under the high AC electric field and gather in the higher electric field. Thereby it is easy to form a bridge across the oil gap, resulting in excessive partial discharge and even insulation breakdown [20,26]. A lot of work was done in the purpose of improving the frequency-dependent properties such as relative permittivity [27], DC resistivity [23] and dissipation factor [22], and thermal properties of insulating oil [22,28,29] by adding particles of nanoscale. However, few publications has dealt with the influence of particles of micrometer size on the breakdown voltage and frequency-dependent dielectric property of vegetable insulating oil up to now. With the rising interests in application of vegetable insulating oil in large power transformers, it is necessary to investigate the influence of particles of micrometer size on the basic insulating performance of vegetable insulating oil.

The object of this paper is to investigate the influence of copper particles of micrometer size on the breakdown and frequency-dependent dielectric properties of vegetable insulating oil. Mineral insulating oil contaminated with copper particles was taken as a reference to obtain the difference between vegetable and mineral insulating oil. The research work could provide some guidance on transformer maintenance and be conductive to establishing corresponding standards concerning the limits of particle number for vegetable insulating oil in power transformers.

\section{Experiments}

\subsection{Materials}

A type of vegetable insulating oil refined from rapeseed oil was used in this research work. It was obtained after three refinement procedures, i.e., alkaline refinement, bleaching, and vacuum distillation [21]. The traditional Naphthenic-based Karamay 25\# mineral insulating oil from PetroChina Co. Ltd. (Beijing, China) was also adopted in the research work for comparison with vegetable insulating oil. The basic properties of the insulating oils are presented in Table 1.

Since the copper particles of micrometer size are common conductive particles in transformer oil, copper particles were used as the typical contaminants in the experiments. Four kinds of copper particles of different median diameters were used in this experiment, i.e., $\mathrm{Cu}$-I, $\mathrm{Cu}-\mathrm{II}, \mathrm{Cu}-\mathrm{III}$ and $\mathrm{Cu}-\mathrm{IV}$, with a median diameter of 3,10,37 and $60 \mu \mathrm{m}$, respectively. The copper particles were purchased directly from the manufacturer (Hongyu New Materials. Co. Ltd., Beijing, China). Median diameter is a measure of the size distribution of the copper particles, which denotes the diameter at which the cumulative size distribution percentage reaches $50 \%$. The size distribution is measured by a granulometer (Malvern, Worcestershire, UK). Figure 1 shows a typical size distribution of copper particles whose median diameter is about $37 \mu \mathrm{m}$. 
Table 1. Basic properties of insulating oils.

\begin{tabular}{ccc}
\hline \multirow{2}{*}{ Parameter } & \multicolumn{2}{c}{ Value } \\
\cline { 2 - 3 } & Vegetable Insulating Oil & Mineral Insulating Oil \\
\hline Appearance & Light yellow & Transparent \\
Density $\left(\mathrm{g} \cdot \mathrm{cm}^{-3}, 20^{\circ} \mathrm{C}\right)$ & 0.90 & $<0.895$ \\
Kinematic viscosity $\left(\mathrm{mm}^{2} \cdot \mathrm{s}^{-1}, 40^{\circ} \mathrm{C}\right)$ & 43.0 & $\leq 13.0$ \\
Pour point $\left({ }^{\circ} \mathrm{C}\right)$ & -18 & $\leq-22$ \\
Flash point $\left({ }^{\circ} \mathrm{C}\right)$ & 325 & $\geq 135$ \\
Acid value $\left(\mathrm{mg} \mathrm{KOH} \cdot \mathrm{g}^{-1}\right)$ & 0.03 & $\leq 0.01$ \\
Interfacial tension $\left(\mathrm{mN} \cdot \mathrm{m}^{-1}\right)$ & 30 & $\geq 40$ \\
Dissipation factor $\left(90^{\circ} \mathrm{C}\right)$ & $2.0 \%$ & $\leq 0.1 \%$ \\
Relative permittivity $\left(90^{\circ} \mathrm{C}\right)$ & 2.9 & 2.2 \\
Volume resistivity $(\Omega \cdot \mathrm{m})$ & $2 \times 10^{10} / 90^{\circ} \mathrm{C}$ & $7 \times 10^{11} / 25^{\circ} \mathrm{C}$ \\
\hline
\end{tabular}

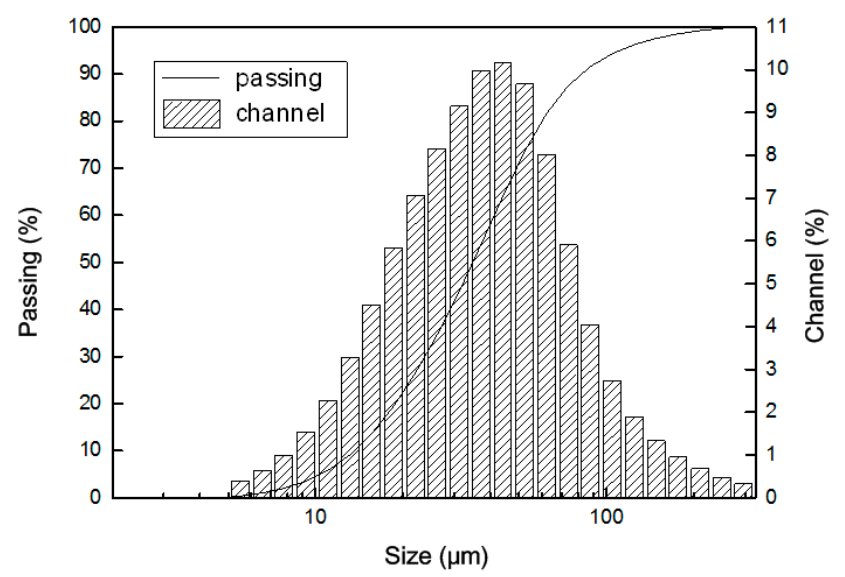

Figure 1. Typical size distribution plot of copper particles.

Figure 2 presents the scanning electron microscope (SEM) (ZEISS, Oberkochen, Germany) images of copper particles and the corresponding energy dispersive spectrometer (EDS) (Oxford Instruments, Oxfordshire, UK) measurement results attached to the SEM. The EDS measurement results indicate that the surface of the copper particles is oxidized, with the mass percentage of Oxygenium being $0.62 \%$.

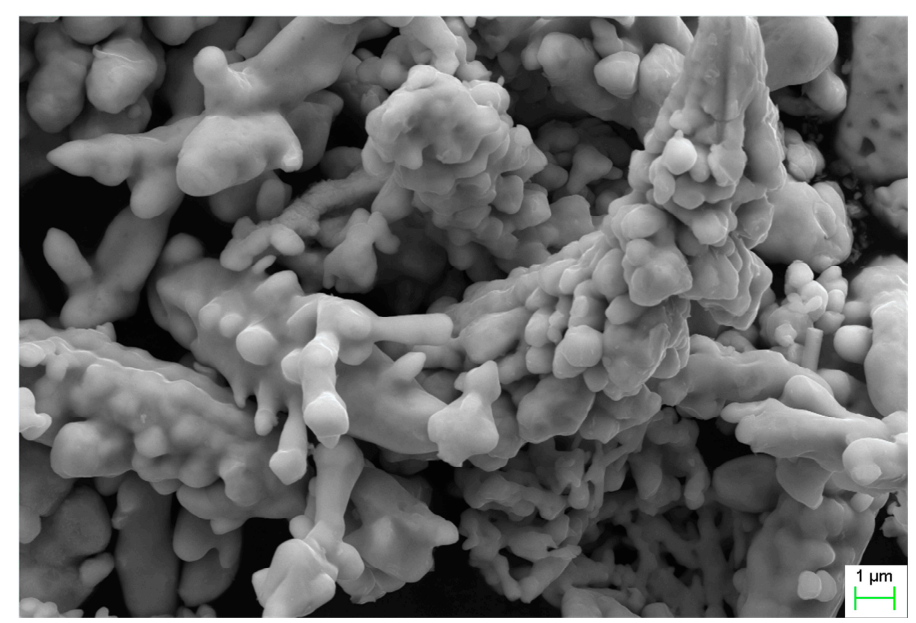

(a)

Figure 2. Cont. 


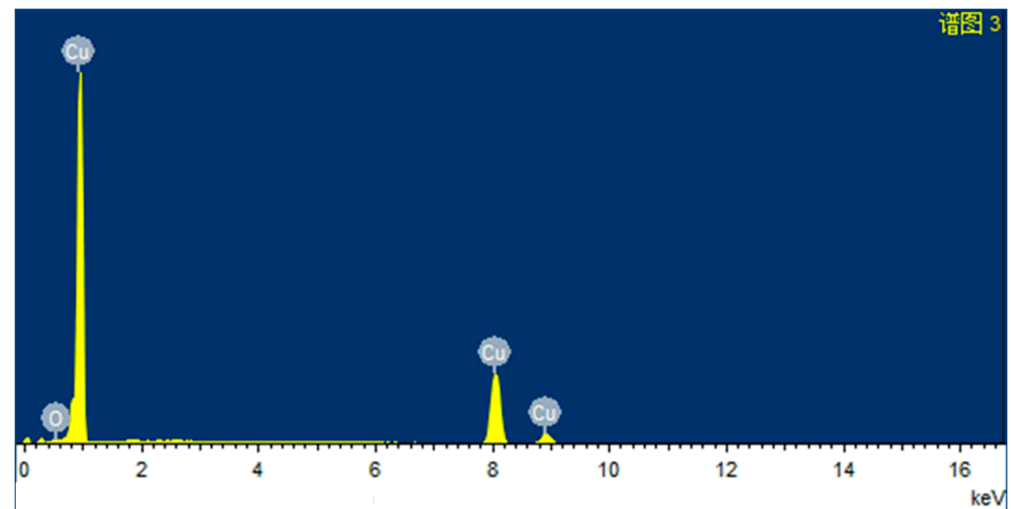

(b)

Figure 2. (a) Scanning electron microscope (SEM) image and (b) Energy dispersive spectrometer (EDS) results of copper particles.

\subsection{Preparation of Oil Samples}

The vegetable insulating oil was put into a vacuum drying chamber under a pressure of $50 \mathrm{~Pa}$ and $90{ }^{\circ} \mathrm{C}$ for $48 \mathrm{~h}$ to be degassed and dehydrated. Thereafter, the transformer oil was filtered with a polytetrafluoroethylene filter membrane with a pore diameter of $1 \mu \mathrm{m}$ to avoid the influence of particles in as-received oil on its breakdown voltage and dielectric performance. The vegetable insulating oil was then contaminated with copper particles of different concentrations. For the oil samples used in the breakdown test, the particle concentration was measured with particle number $N$ in per 100 $\mathrm{mL}$ oil to investigate the relation between breakdown voltage and particle number. $N$ was fixed near the number of 1000, 10,000, 100,000, 500,000 and 1000,000 as possible. For Cu-IV, as the mass weigh of 1000,000 copper particle is too large, so the particle number was set to $1000,10,000,50,000$, 100,000 and 200,000. For the oil samples used in the frequency-dependent dielectric property test, only $\mathrm{Cu}-\mathrm{II}$ was used to contaminate the oil as the particles in insulating oil mainly lie in the range of 5-15 $\mu \mathrm{m}$ [6] The particle concentration was traditionally measured with the volumetric concentrations. The mass weights of copper particles in per $100 \mathrm{~mL}$ of contaminated vegetable insulating oil are $0.1 \mathrm{~g}$, $0.5 \mathrm{~g}$ and $1 \mathrm{~g}$, thus yielding three different volumetric concentrations, i.e., $0.011 \%, 0.056 \%$ and $0.112 \%$, respectively. The moisture content of the vegetable insulating oil was measured and controlled within $30 \mu \mathrm{g} / \mathrm{mL}$ to exclude the interference of water on the experiment results as much as possible.

\subsection{Measurements}

The AC breakdown voltage of contaminated oil at $50 \mathrm{~Hz}$ was measured by an automatic electrical breakdown tester IJJD-80 (Ruixin Electrical Test Equipment Co. Ltd., Wuhan, China) in accordance with ASTM (American Society for Testing and Materials) D877 standard, but the rising speed of AC voltage is $2 \mathrm{kV} / \mathrm{s}$ and the oil gap between two brass disk electrodes is $2.5 \mathrm{~mm}$. It should be noted that since the gaseous by-products of breakdowns will affect the experimental results, enough time should be given for them to be expelled from the oil gap. The time interval between two successive breakdowns is 5 minutes. A series of six AC breakdown voltages for each of the three samples were measured to obtain 18 breakdown voltage data at each particle contamination level. The mean value of the 18 breakdown voltage data was determined as the dielectric strengths of the oil sample.

The dielectric parameters including relative permittivity, dissipation factor and volume resistivity of vegetable insulating oil with various copper volumetric concentrations versus frequency were measured using a Concept 80 broadband dielectric spectrometer (Novocontrol Technologies GmbH \& Co. KG, Montabaur, Germany). The volume resistivity was obtained with the value of the applied AC voltage and current, which is different from the DC resistivity. In this work, the test frequencies of 
the experiment are between $10^{-2} \mathrm{~Hz}$ and $10^{6} \mathrm{~Hz}$ and the temperature during the experiment is about $18^{\circ} \mathrm{C}$ to $20^{\circ} \mathrm{C}$.

\section{Experimental Results}

\subsection{Breakdown Voltage of Vegetable Insulating Oil Contaminated with Copper Particle}

Figure 3 shows the breakdown voltage of insulating oil contaminated with copper particles. The linear fitting was used to fit the breakdown voltage and the logarithm of particle number $(\lg N)$. The fitting results are presented in Table 2, where $R^{2}$ denotes the correlation coefficient.

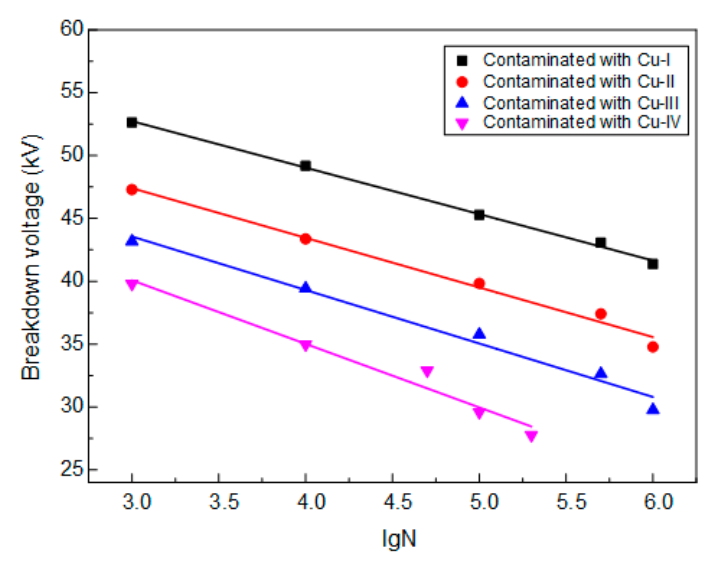

(a)

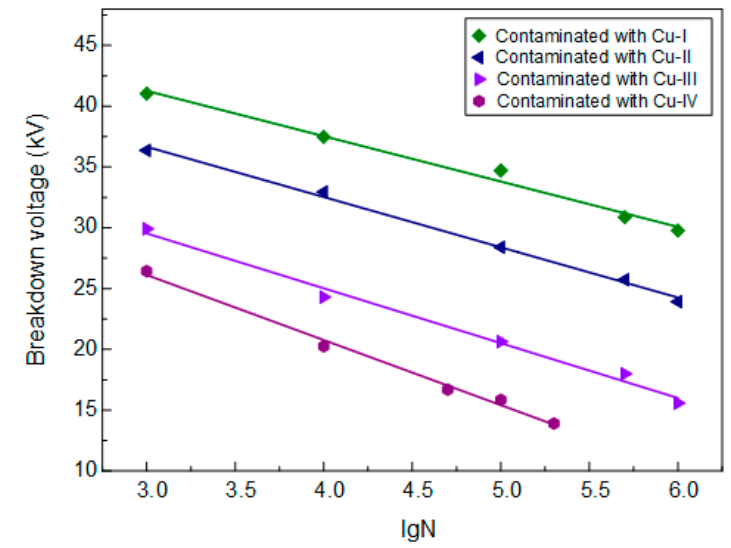

(b)

Figure 3. AC breakdown voltage of (a) vegetable insulating oil and (b) mineral insulating oil contaminated with copper particles.

Table 2. Influence of copper particles on AC breakdown voltage of vegetable insulating oil.

\begin{tabular}{|c|c|c|c|c|}
\hline \multirow{2}{*}{ Particle Size $(\mu \mathrm{m})$} & \multicolumn{2}{|c|}{ Fitting Expression } & \multicolumn{2}{|c|}{$R^{2}$} \\
\hline & Vegetable Oil & Mineal Oil & Vegetable Oil & Mineal Oi \\
\hline 3 & $U=-3.70 \lg N+63.82$ & $U=-3.73 \lg N+52.46$ & 0.9976 & 0.9878 \\
\hline 10 & $U=-3.95 \lg N+59.25$ & $U=-4.14 \lg N+49.08$ & 0.9879 & 0.9959 \\
\hline 37 & $U=-4.26 \lg N+56.33$ & $U=-4.52 \lg N+43.09$ & 0.9819 & 0.9900 \\
\hline 60 & $U=-5.05 \lg N+55.24$ & $U=-5.35 \lg N+42.18$ & 0.9698 & 0.9931 \\
\hline
\end{tabular}

The presence of particles has significant influence on the breakdown strength of insulating oil. The AC breakdown voltage of insulating oil decreases with the increase of particle number. The AC breakdown voltage is lower and its descending rate is greater when the median size of copper particles is greater. It should be noted that the breakdown voltage of contaminated mineral insulating reduces faster than that of contaminated vegetable insulating oil with the increase of particle number, which suggests a different limit of particle number should be established for vegetable insulating oil.

To further investigate the influence of copper particles on the breakdown properties of vegetable insulating oil, the experimental data of breakdown voltage were analyzed with a two-parameter Weibull distribution [30,31]. Its cumulative distribution function is:

$$
F(U)=1-\exp \left(-(U / \alpha)^{\beta}\right), U>0, \alpha>0, \beta>0
$$

where $U$ represents the random variable, i.e., the breakdown voltage in this paper, $\alpha$ represents scale parameter, and $\beta$ represents shape parameter. Parameter $\alpha$ indicates an average or characteristic value of the random variable, and parameter $\beta$ characterizes the dispersion of the data. 
The breakdown voltage of vegetable insulating oil contaminated with $\mathrm{Cu}$-II are taken as an example and the situation in other cases is similar. Figure 4 presents the Weibull probability plot of breakdown voltage data of vegetable insulating oil contaminated with $\mathrm{Cu}$-II. Most of the data points are scattered besides both sides of the line and few data are far away from the line. This indicates the breakdown voltage data basically obey the Weibull distribution. The shape parameter and scale parameter of breakdown voltage was then estimated using the maximum likelihood estimation method. Meanwhile, the AC breakdown voltage corresponding to a breakdown probability of $63.2 \%, 50 \%$ and $5 \%$ were obtained with the Weibull distribution, as shown in Table 3, where $P$ stands for probability. The breakdown voltages corresponding to the breakdown probability of $63.2 \%, 50 \%$ and $5 \%$ all decrease with increasing copper particle concentration and the breakdown probability of insulating oil contaminated with more copper particles is greater under the same voltage. It can be concluded that the breakdown strength of vegetable insulating oil is vulnerable to copper particles and the presence of particles increases the possibility of breakdown of vegetable insulating oil.

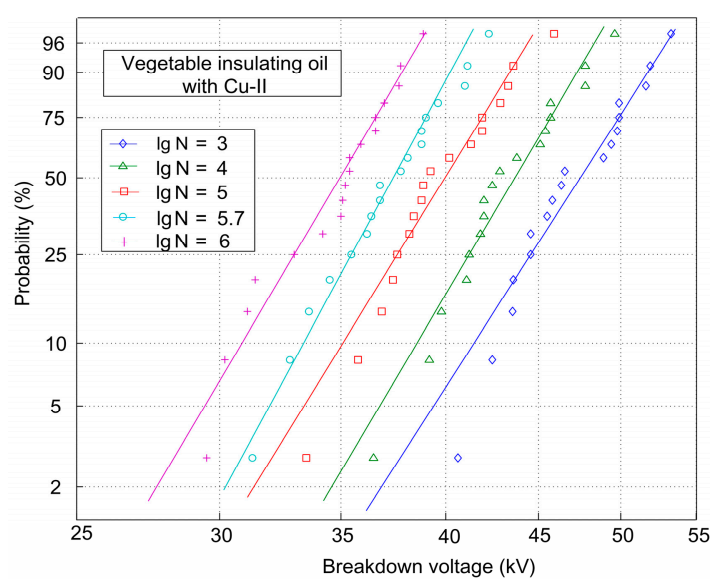

Figure 4. Weibull probability plot of AC breakdown voltage of vegetable insulating oil contaminated with Cu-II.

Table 3. Breakdown voltage of vegetable oil contaminated with $\mathrm{Cu}-\mathrm{II}$ of different numbers.

\begin{tabular}{cccc}
\hline \multirow{2}{*}{ Logarithm of Particle Number $(\lg N)$ AC Breakdown Voltage $(\mathbf{k V})$} \\
\cline { 2 - 4 } & $\mathbf{P = \mathbf { 6 3 . 2 } \%}$ (Scale Parameter) & $\boldsymbol{P = 5 0 \%}$ & $\boldsymbol{P}=\mathbf{5 \%}$ \\
\hline 3 & 48.82 & 45.58 & 38.71 \\
4 & 44.84 & 43.73 & 36.21 \\
5 & 41.23 & 40.01 & 32.83 \\
5.7 & 38.76 & 37.46 & 31.61 \\
6 & 35.95 & 35.02 & 28.96 \\
\hline
\end{tabular}

\subsection{Frequency-Dependent Dielectric Property of Vegetable Insulating Oil Contaminated with Copper Particle}

Figure 5 depicts the volume resistivity of oil versus frequency. The volume resistivity of vegetable oil decreases with the increase of frequency between $10^{-2} \mathrm{~Hz}$ and $10^{6} \mathrm{~Hz}$, but exhibits some difference at frequencies below and above $10^{2} \mathrm{~Hz}$. The volume resistivity decreases dramatically at frequencies below $10^{2} \mathrm{~Hz}$ while it come to a slight decrease at the frequencies above $10^{2} \mathrm{~Hz}$, regardless of the copper volumetric concentration. For vegetable oil contaminated with $\mathrm{Cu}$-II, the influence of copper particle concentration on volume resistivity is inconspicuous at frequencies above $10 \mathrm{~Hz}$ while it begin to become significant at frequencies below $10 \mathrm{~Hz}$. A similar trend can be also found in volume resistivity of mineral oil. 


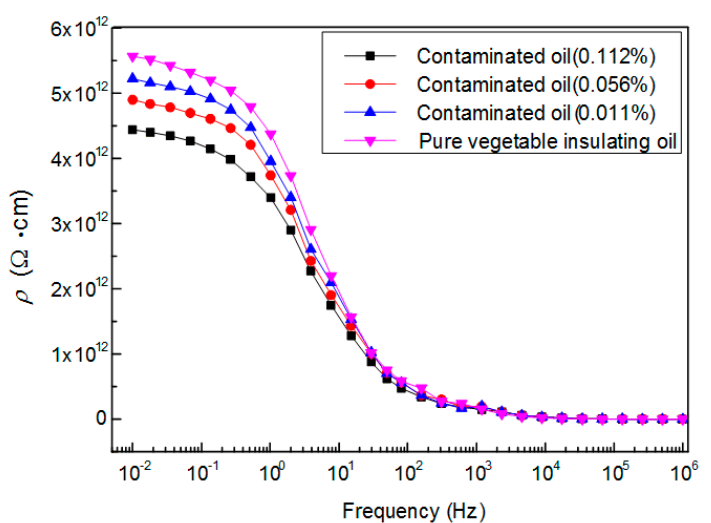

(a)

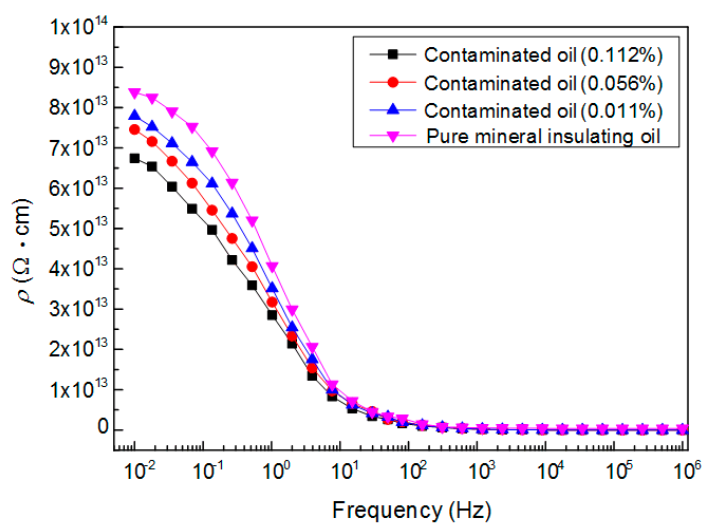

(b)

Figure 5. Volume resistivity of (a) vegetable insulating oil and (b) mineral insulating oil versus frequency with different copper volumetric concentrations.

Figure 6 plots the relative permittivity of oil contaminated with $\mathrm{Cu}-\mathrm{II}$ of different volumetric concentrations versus frequency. The relative permittivity of vegetable insulating oil decreases with the increase of frequency between $10^{-2} \mathrm{~Hz}$ and $10^{6} \mathrm{~Hz}$. It decreases dramatically at frequencies below $10 \mathrm{~Hz}$ while its decreasing tendency at the frequencies above $10 \mathrm{~Hz}$ becomes inconspicuous. The relative permittivity of the oil exhibits an increase with the increase of copper volumetric concentration at frequencies between $10^{-2} \mathrm{~Hz}$ and $10^{6} \mathrm{~Hz}$ and the increasing tendency is much more significant at frequencies lower than $10 \mathrm{~Hz}$. A similar trend can be also found in relative permittivity of mineral oil.

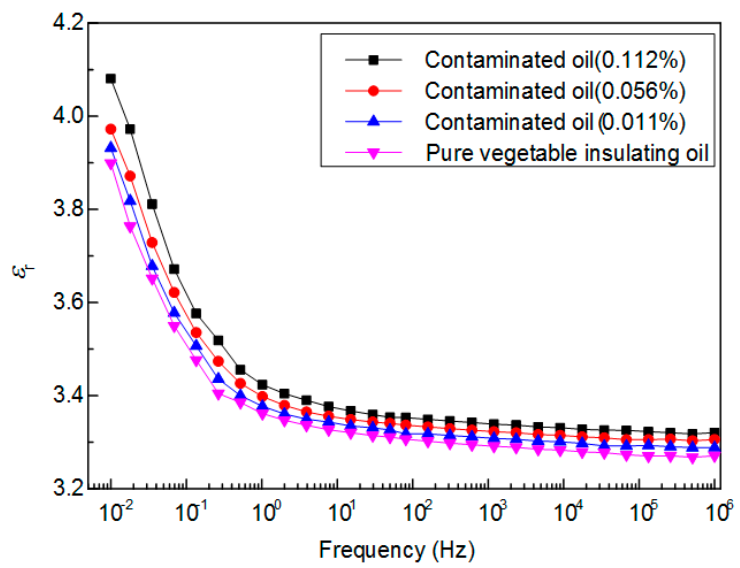

(a)

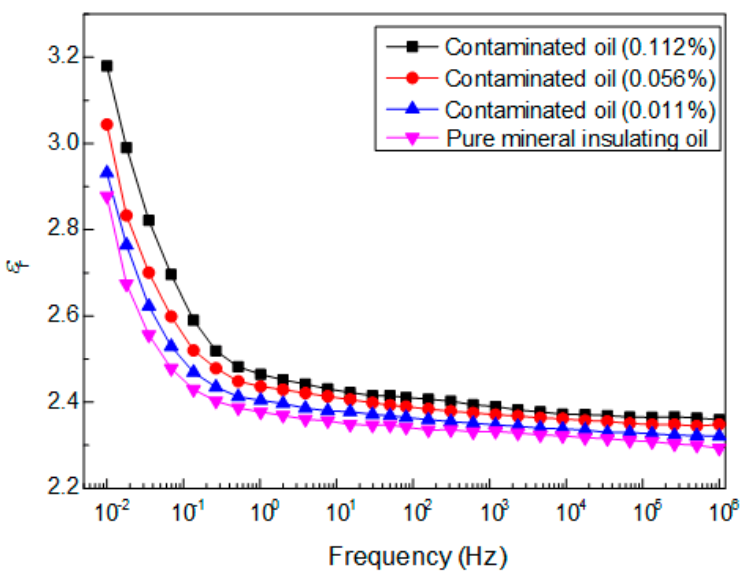

(b)

Figure 6. Relative permittivity of (a) vegetable insulating oil and (b) mineral insulating oil versus frequency with different copper volumetric concentrations.

Figure 7 plots the dissipation factor of oil contaminated with $\mathrm{Cu}-\mathrm{II}$ of different volumetric concentrations versus frequency. The dissipation factor of vegetable insulating oil decreases with the increase of frequency between $10^{-2} \mathrm{~Hz}$ and $10^{6} \mathrm{~Hz}$. It decreases dramatically at low frequencies, whereas its descending rate becomes relatively small at frequencies above $1 \mathrm{~Hz}$. For samples of different copper volumetric concentration, the difference in the dissipation factor of oil at a certain frequency is very small at frequencies greater than $1 \mathrm{~Hz}$. The influence of copper particle concentration on the dissipation factor, however, begins to become obvious and the difference among the values of dissipation factor increases with the decrease of frequency, especially when the frequency is below $10^{-1} \mathrm{~Hz}$. A similar trend can be also found in dissipation factor of mineral oil. 


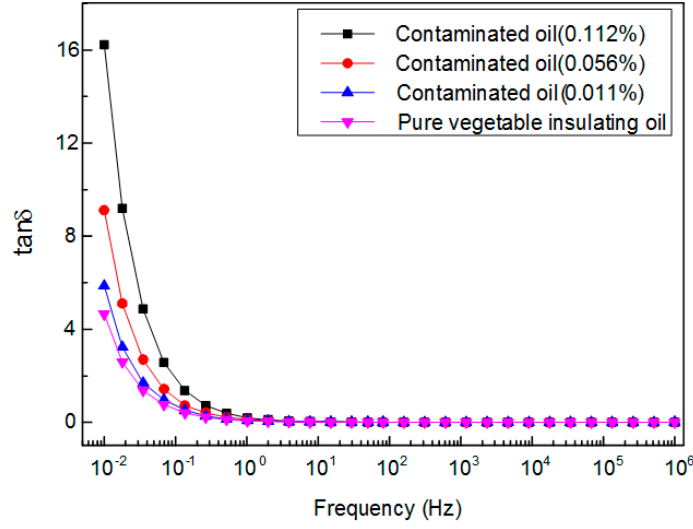

(a)

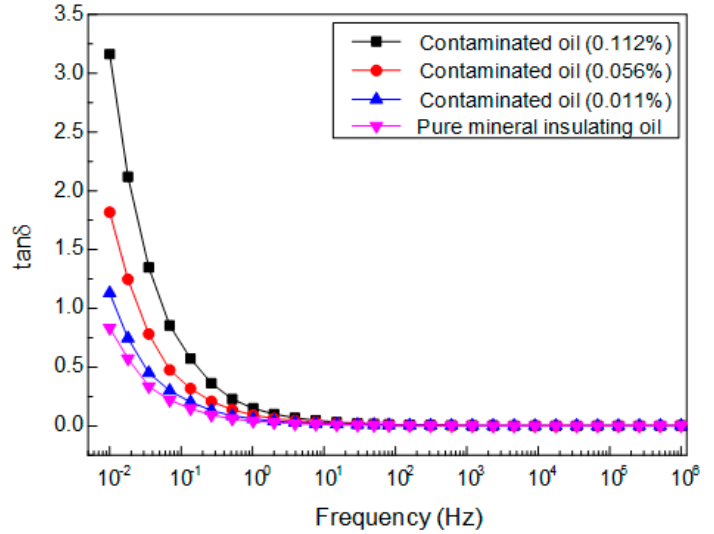

(b)

Figure 7. Dissipation factor of (a) vegetable insulating oil and (b) mineral insulating oil with different copper volumetric concentrations versus frequency.

\section{Analysis and Discussion}

\subsection{Influence of Copper Particles on AC Breakdown Voltage of Vegetable Oil}

With consideration at a macroscopical level, the decrease of breakdown voltage can be explained as follows. The copper particles will be charged, move and agglomerate in regions of high electric field under the electric force. It is likely for the copper particles to form partial "chains" that line up along the power lines. It is well known that the "weak link" like the partial "chains" between the oil gap, gas bubbles or surface defects is likely to initiate the partial discharge or partial breakdown as it distorts and increases the local electric field, which will finally result in breakdown of oil gap. With the increase in copper particle number, the possibility of partial discharge and breakdown will be increased because of the weak link, thus the breakdown voltage is reduced.

The breakdown voltage of insulating oil contaminated with copper particles of greater median diameter is larger. This may be because that greater surface area of copper particles can induce and carry more charges, which is helpful to form the "weak link" between the oil gap. It is pointed out that the breakdown strength of oil with particles suspending in it is to inversely proportional to $r^{3}$, where $r$ denotes the radius of the particles [32]. Thereby it was observed that the breakdown voltage of oil was lower when copper particles of greater size were added.

The descending rate of breakdown voltage of vegetable oil is smaller than that of mineral oil, which indicates that the breakdown voltage of vegetable oil is less sensitive to copper particles. This difference can be attributed to the relatively greater viscosity of vegetable oil [9]. The movement of the copper particles under electric field is restricted by the viscous resistance of the oil. Low viscosity of oil can increase the mobility of charge carriers and is helpful in the formation of gaseous bubbles [33], which are likely to promote the breakdown of oil.

\subsection{Influence of Copper Particles on Frequency-Dependent Dielectric Property of Vegetable Oil}

\subsubsection{Volume Resistivity}

The Maxwell conductivity formula of solid-liquid mixed phase is introduced to analyze the influence of copper particles on the volume resistivity of vegetable insulating oil. It is commonly used in characterizing the conductivity of solid-liquid mixed dielectric [34]. The Maxwell conductivity formula is as follows $[35,36]$ :

$$
\gamma=\gamma_{f}\left[1+\frac{3 \varphi}{(\alpha+2) /(\alpha-1)-\varphi}\right]
$$


where $\gamma$ and $\gamma_{f}$ are the conductivity of insulating oil which are contaminated and are not contaminated, respectively; $\alpha$ is the conductivity ratio of copper particles to insulating oil; $\varphi$ is the volumetric concentration of copper particles in contaminated oil.

The conductivity of copper particles is about $5.9 \times 10^{7} \mathrm{~S} / \mathrm{m}$, whereas the vegetable insulating oil is a dielectric with a conductivity of about $1 \times 10^{-10} \mathrm{~S} / \mathrm{m}$. Obviously, the conductivity of copper is much greater than that of oil, so Equation (2) could be rewritten as:

$$
\gamma=\gamma_{f}[1+3 \varphi /(1-\varphi)]
$$

According to (3), when $\varphi$ is smaller than $1 / 2$, the conductivity of contaminated vegetable insulating oil increases with the increase in copper volumetric concentration, and therefore the volume resistivity decreases correspondingly. This could also explain the decrease of breakdown strength of vegetable insulating oil in the presence of copper particles.

The greater difference in volume resistivity of contaminated oil at lower frequencies can be explained as follows. The duration of each half cycle of the electrical field is long and the charged copper particles could reach the electrode under the electric field at low frequencies. This can promote the formation of a "weak link" and increase the conduction current, thus decreasing the volume resistivity. With the increase of frequency, the duration of each half cycle of the electrical field decreases and the probability for charged copper particles to reach electrode decreases. This may be the reason why smaller difference in volume resistivity was observed among vegetable insulating oil samples contaminated with copper particles of different volumetric concentrations at frequencies greater than $10 \mathrm{~Hz}$.

\subsubsection{Relative Permittivity}

Vegetable oils adopted in this research work are mixtures of triglycerides, which are formed by combining one molecule of glycerol with three molecules of fatty acid. There are carboxyl, acyl and other polar groups in the vegetable oil molecule and three of the fatty acids in the triglycerides are usually different. Consequently, the vegetable insulating oil is a weak polar liquid dielectric. There are inner polarization and dipole orientation polarization of vegetable oil molecules under the AC electric field. At the same time, the molecules of vegetable insulating oil have permanent dipole moment.

The copper particle in oil will be induced under an AC electric field. Positive and negative surface polarization charges will gather at two sides of a copper particle, making the particle charged. From the point of microscopic view, the charged copper particle under the electric field has two motion tendencies. One is the random thermal motion, and the other is the orientation along electric field. The motion tendency of charged copper particle is similar with that of a polar molecule, so the copper particle could be considered as a dielectric molecule which has polarization. Namely, the charged copper particle can be seen as a polar molecule with electric dipole moment $\left(\mu_{\mathrm{c}}\right)$ and it has dipole orientation polarization, as shown in Figure 8 [27,37].

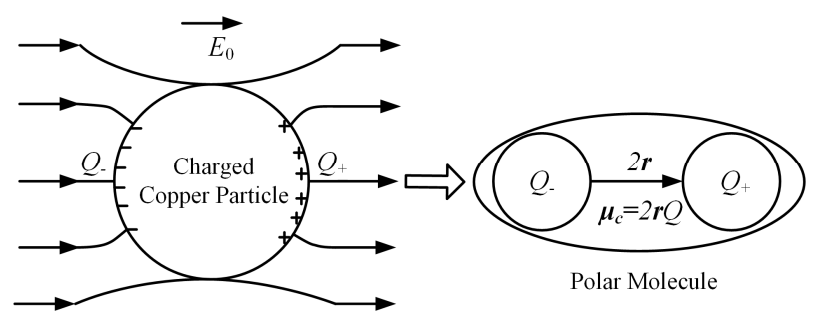

Figure 8. Charged copper particle modeled as a polar molecule.

Therefore, for vegetable insulating oil contaminated with copper particles under AC electric field, both vegetable oil molecules and copper particles will be polarized. There could be three types of 
polarization in vegetable insulating oil contaminated with copper particles: the inner polarization and dipole orientation polarization of vegetable oil molecules, the inner polarization and dipole orientation polarization of copper particles modeled as polar molecules, and the space charge polarization at the interface of vegetable insulating oil and copper particles [38].

The space charge polarization caused by copper particles plays a dominant role at the test frequencies between $10^{-2} \mathrm{~Hz}$ and $10 \mathrm{~Hz}$, as the time needed for space charge polarization is about $10^{-1}$ seconds to a few hours [39]. With the increase of frequency, the motion of space charge cannot keep up with the change of electric field direction and the space charge polarization will be deficiently accomplished. Therefore, the relative permittivity of contaminated vegetable insulating oil decreases with the increase of frequency below $10 \mathrm{~Hz}$. At frequencies above $10 \mathrm{~Hz}$, the space charge polarization can hardly complete and the inner polarization and dipole orientation polarization become dominant in contaminated oil. The time needed for inner polarization and dipole orientation polarization in contaminated oil is very small and the polarization can be sufficiently accomplished, so the relative permittivity of contaminated vegetable insulating oil almost remains the same at the frequencies greater than $10 \mathrm{~Hz}$.

At frequencies below $10 \mathrm{~Hz}$, with the increase in copper volumetric concentration, more copper particles will have space charge polarization in per unit volume of contaminated oil, and thus contribute more to the relative permittivity. Thereby the relative permittivity of contaminated vegetable insulating oil increases with the increase of copper volumetric concentration especially at low frequencies, as shown in Figure 6.

\subsubsection{Dissipation Factor}

The dielectric loss of vegetable insulating oil consists of conduction loss and polarization loss, and it can be expressed as follows:

$$
\tan \delta=\tan \delta_{P}+\tan \delta_{G}=\frac{\varepsilon_{s}-\varepsilon_{\infty}}{\varepsilon_{\infty} \omega \tau}+\frac{\gamma}{\omega \varepsilon_{0} \varepsilon_{\infty}} \propto \frac{1}{\omega}
$$

where $\tan \delta_{P}$ is the dissipation factor caused by polarization loss; $\tan \delta_{G}$ is the dissipation factor caused by conduction loss; $\varepsilon_{S}$ is the steady state permittivity; $\varepsilon_{\infty}$ is the permittivity at frequency of positive infinity; $\gamma$ is the equivalent conductivity under AC electric field; $\omega$ is the angle frequency; $\tau$ is the relaxation time. It can be seen from Equation (4) that the dielectric loss of vegetable insulating oil is greater at lower frequencies and decreases with the increase of frequency. The dielectric loss of vegetable insulating oil tends to be zero as the frequency tends to be infinity.

Considering the polarization types of vegetable insulating oil contaminated with copper particles, the dipole orientation polarization of vegetable insulating oil molecules and charged copper particles is relaxation polarization in the contaminated oil. At lower frequencies, the dipole orientation polarization of vegetable insulating oil molecules and copper particles can keep up with the change of electric field direction. The polarization loss in contaminated oil is therefore very small and can be neglected. The dielectric loss caused by conduction loss is dominant at lower frequencies [40], which is as follows:

$$
\tan \delta=\frac{4 \pi K \gamma}{\omega \varepsilon_{r}}
$$

where $\gamma$ is the equivalent conductivity of contaminated vegetable insulating oil under the AC electric field, and $K$ is a constant. The dissipation factor of contaminated vegetable insulating oil at lower frequencies is proportional to the equivalent conductivity $\gamma$. As analyzed in Section 4.2.1, $\gamma$ increases with the increase of copper volumetric concentration. Moreover, the polarization loss caused by copper particles under the AC electric field increases with the increase in copper volumetric concentration. Thereby the dissipation factor increases with increasing copper volumetric concentration at lower frequencies, as shown in Figure 7. As the frequency increases, the polarization loss in contaminated 
oil becomes dominant gradually. But with the increase of angular frequency $\omega$, the dissipation factor which is inversely proportional to the angular frequency reduces and is close to zero.

It should be noted that there should be an extreme value of dissipation factor as the frequency increases according to (6). The extreme value is obtained when the condition $\omega \tau \approx 1$ is satisfied. As the relaxation time $\tau$ of both vegetable oil and mineral oil is very small, only when the frequency is greater than $\mathrm{MHz}$ will the extreme value of the dissipation factor appear. As the testing frequency is in the range of $10^{-2}-10^{6} \mathrm{~Hz}$ in this work, the extreme value wasn't observed.

$$
\tan \delta=\frac{\left(\varepsilon_{S}-\varepsilon_{\infty}\right) \omega \tau}{\varepsilon_{S}+\varepsilon_{\infty} \omega^{2} \tau^{2}}
$$

\section{Conclusions}

The AC breakdown voltage and the frequency-dependent dielectric properties of vegetable and mineral insulating oil contaminated with copper particles were measured and analyzed in this work. The following specific conclusions may be obtained:

The AC breakdown voltage of vegetable insulating oil decreases as the result of an increase in copper particle number. The AC breakdown voltage is lower when the median size of copper particles is greater, which indicates that copper particles of greater median size have more significant influence on the breakdown strength of vegetable insulating oil. The reduction in AC breakdown voltage of vegetable oil is less sensitive to the copper particles compared with that of mineral oil because of its greater viscosity, which is adverse to the initiation of partial discharge or breakdown of oil.

The relative permittivity and dissipation factor increase with the increase in volumetric concentration of copper particles while the volume resistivity decreases. The influence of copper particles on these three parameters is significant at lower frequencies while this influence becomes inconspicuous at higher frequencies: the copper particles have much more influence on volume resistivity at frequencies below $10 \mathrm{~Hz}$ as there is enough time for the charged copper particles to reach the electrode and it is more likely to increase the conduction current. The influence of copper particles on relative permittivity is more significant at frequencies below $10 \mathrm{~Hz}$ as the space charge polarization of copper particles is the dominant polarization at this frequency range. More copper particles with more space charge polarization in per unit volume of contaminated oil contribute more to the relative permittivity. The influence of copper particles on the dissipation factor is more obvious at frequencies below $10^{-1} \mathrm{~Hz}$ as the dielectric loss caused by conduction loss is dominant at lower frequencies and this dielectric loss is proportional to the equivalent conductivity of the contaminated oil.

Acknowledgments: The authors thank the National Natural Science Foundation of China (No. 51425702 and No. 51321063) and the 111 Project of China (Grant No. B08036) for the financial support provided. The authors also thank the anonymous reviewers and the editor for their valuable advice and comments on our manuscript.

Author Contributions: The research work presented in this paper was collaboratively conducted by all authors. Jian Li and Feipeng Wang designed the experiment; Jing Zhang organized the experiments, carried out the experiments with Hehuan Ran, analyzed the test results with Dali Huang and wrote this paper. Feipeng Wang revised the paper.

Conflicts of Interest: The authors declare no conflict of interest.

\section{References}

1. Bandara, K.; Ekanayake, C.; Saha, T.K. Modelling the dielectric response measurements of transformer oil. IEEE Trans. Dielectr. Electr. Insul. 2015, 22, 1283-1291. [CrossRef]

2. Hopkinson, P.; Dix, L.; McShane, C.P.; Moore, H.R.; Moore, S.; Murphy, J.; Prevost, T.; Beaster, B. Progress report on natural esters for distribution and power transformers. In Proceedings of the 2009 IEEE Power \& Energy Society General Meeting, Calgary, AB, Canada, 26-30 July 2009; pp. 1-3.

3. Nagashree, A.N.; Champa, V.; Sumangala, B.V.; Nagabhushana, G.R. Suitability of natural vegetable seed oil as liquid dielectric coolant in an insulation system. In Proceedings of the 2015 International Conference 
on Emerging Research in Electronics, Computer Science and Technology (ICERECT), Mandya, India, 17-19 December 2015; pp. 429-434.

4. Rozga, P.; Stanek, M. Comparative analysis of lightning breakdown voltage of natural ester liquids of different viscosities supported by light emission measurement. IEEE Trans. Dielectr. Electr. Insul. 2017, 24, 991-999. [CrossRef]

5. Li, J.; Zhang, Z.; Grzybowski, S.; Liu, Y. Characteristics of moisture diffusion in vegetable oil-paper insulation. IEEE Trans. Dielectr. Electr. Insul. 2012, 19, 157. [CrossRef]

6. Aubin, J. Effect of Particles on Transformer Dielectric Strength; Cigré: Paris, France, 2000.

7. Insulating Liquids-Methods for Counting and Sizing Particles. Available online: https://shop.standards. ie/preview/is/en/2008/i.s.en60970-2008.pdf?sku=1129729 (accessed on 5 July 2017).

8. Wang, X.; Wang, Z.D. Particle effect on breakdown voltage of mineral and ester based transformer oils. In Proceedings of the Conference on Electrical Insulation and Dielectric Phenomena, Quebec, QC, Canada, 26-29 Octomber 2008; pp. 598-602.

9. Wang, X.; Wang, Z.D.; Noakhes, J. Motion of conductive particles and the effect on AC breakdown strengths of esters. In Proceedings of the 2011 IEEE International Conference on Dielectric Liquids, Trondheim, Norway, 26-30 June 2011; pp. 1-4.

10. Sinan, S.; Jasni, J.; Azis, N.; Kadir, A.; Abidin, M.Z.; Mohtar, M. Effect of particles on the AC breakdown voltage of palm oil and coconut oil. Appl. Mech. Mater. 2015, 793, 70-74. [CrossRef]

11. Miners, K. Particles and moisture effect on dielectric strength of transformer oil using vde electrodes. IEEE Trans. Power Appar. Syst. 1982, 101, 751-756. [CrossRef]

12. Mathes, K.; Atkins, J. Influence of particles on partial discharges and breakdown in oil. In Proceedings of the International Conference on Electrical Insulation, Philadelphia, PA, USA, 12-14 June 1978; pp. 226-231.

13. Lu, W.; Liu, Q. Effect of cellulose particles on impulse breakdown in ester transformer liquids in uniform electric fields. IEEE Trans. Dielectr. Electr. Insul. 2015, 22, 2554-2564. [CrossRef]

14. Farooq, K. The effect of particulate and water contamination on the dielectric strength of insulating oils. In Proceedings of the Conference Record of the 1996 IEEE International Symposium on Electrical Insulation, Montreal, QC, Canada, 16-19 Jun 1996; pp. 728-732.

15. Krins, M.; Borsi, H.; Gockenbach, E. Influence of carbon particles on the breakdown voltage of transformer oil. In Proceedings of the 12th International Conference on Conduction and Breakdown in Dielectric Liquids, Roma, Italy, 15-19 July 1996; pp. 296-299.

16. Dascalescu, L.; Mihailescu, M.; Tobazeon, R. Modeling of conductive particle behavior in insulating fluids affected by DC electric fields. IEEE Trans. Ind. Appl. 1998, 34, 66-74. [CrossRef]

17. Krins, M.; Borsi, H.; Gockenbach, E. Impact of carbon particles on the electrical strength of different solid/liquid interfaces in a non-uniform field. In Proceedings of the Conference Record of the 1998 IEEE International Symposium on Electrical Insulation, Arlington, VA, USA, 7-10 June 1998; pp. 623-626.

18. Panov, V.A.; Kulikov, Y.M.; Son, E.E.; Tyuftyaev, A.S.; Gadzhiev, M.K.; Akimov, P.L. Electrical breakdown voltage of transformer oil with gas bubbles. High Temp. 2014, 52, 770-773. [CrossRef]

19. Mahmud, S. Influence of Contamination on the Electrical Performance of Power Transformer Oil; University of Southampton: Southampton, UK, 2015.

20. Mahmud, S.; Chen, G.; Golosnoy, I.; Wilson, G.; Jarman, P. Experimental studies of influence of DC and AC electric fields on bridging in contaminated transformer oil. IEEE Trans. Dielectr. Electr. Insul. 2015, 22, 152-160. [CrossRef]

21. Li, J.; Zhang, Z.; Zou, P.; Grzybowski, S.; Zahn, M. Preparation of a vegetable oil-based nanofluid and investigation of its breakdown and dielectric properties. IEEE Electr. Insul. Mag. 2012, 28, 43-50. [CrossRef]

22. Peppas, G.D.; Bakandritsos, A.; Charalampakos, V.P.; Pyrgioti, E.C.; Tucek, J.; Zboril, R.; Gonos, I.F. Ultrastable natural ester-based nanofluids for high voltage insulation applications. ACS Appl. Mater. Interf. 2016, 8, 25202-25209. [CrossRef] [PubMed]

23. Du, Y.; Lv, Y.; Li, C.; Chen, M.; Zhong, Y.; Zhou, J.; Li, X.; Zhou, Y. Effect of semiconductive nanoparticles on insulating performances of transformer oil. IEEE Trans. Dielectr. Electr. Insul. 2012, 19, 42-45.

24. N'cho, J.; Fofana, I.; Hadjadj, Y.; Beroual, A. Review of physicochemical-based diagnostic techniques for assessing insulation condition in aged transformers. Energies 2016, 9, 367. [CrossRef]

25. Carraz, F.; Rain, P.; Tobazeon, R. Particle initiated breakdown in a quasi-uniform field in transformer oil. IEEE Trans. Dielectr. Electr. Insul. 1995, 2, 1052-1063. [CrossRef] 
26. Mahmud, S.; Chen, G.; Golosnoy, I.; Wilson, G.; Jarman, P. Experimental studies of influence of different electrodes on bridging in contaminated transformer oil. IEEE Trans. Dielectr. Electr. Insul. 2015, 22, 2433-2441. [CrossRef]

27. Miao, J.; Dong, M.; Ren, M.; Wu, X.; Shen, L.; Wang, H. Effect of nanoparticle polarization on relative permittivity of transformer oil-based nanofluids. J. Appl. Phys. 2013, 113, 204103. [CrossRef]

28. Choi, C.; Yoo, H.; Oh, J. Preparation and heat transfer properties of nanoparticle-in-transformer oil dispersions as advanced energy-efficient coolants. Curr. Appl. Phys. 2008, 8, 710-712. [CrossRef]

29. Taha-Tijerina, J.; Narayanan, T.N.; Gao, G.; Rohde, M.; Tsentalovich, D.A.; Pasquali, M.; Ajayan, P.M. Electrically insulating thermal nano-oils using 2D fillers. ACS Nano 2012, 6, 1214-1220. [CrossRef] [PubMed]

30. IEC/IEEE Guide for the Statistical Analysis of Electrical Insulation Breakdown Data (Adoption of IEEE Std 930-2004); IEEE: Piscataway, NJ, USA, 2007; pp. 1-53.

31. Martin, D.; Martin, D.; Wang, Z.; Wang, Z. Statistical analysis of the ac breakdown voltages of ester based transformer oils. IEEE Trans. Dielectr. Electr. Insul. 2008, 15, 1044-1050. [CrossRef]

32. Kuffel, J.; Kuffel, P. High Voltage Engineering Fundamentals; Newnes: Oxford, UK, 2000.

33. Chadband, W.G. From bubbles to breakdown, or vice-versa. In Proceedings of the IEEE 11th International Conference on Conduction and Breakdown in Dielectric Liquids, Baden-Dattwil, Switzerland, 19-23 July 1993; pp. 184-193.

34. Robinson, D.A.; Friedman, S.P. Electrical conductivity and dielectric permittivity of sphere packings: Measurements and modelling of cubic lattices, randomly packed monosize spheres and multi-size mixtures. Phys. A Stat. Mech. Appl. 2005, 358, 447-465. [CrossRef]

35. Zhu, S.; Zareifard, M.; Chen, C.; Marcotte, M.; Grabowski, S. Electrical conductivity of particle-fluid mixtures in ohmic heating: Measurement and simulation. Food Res. Int. 2010, 43, 1666-1672. [CrossRef]

36. Maxwell, J. A Treatise on Electricity and Magnetism; Clarendon Press: Oxford, UK, 1873.

37. Takada, T.; Hayase, Y.; Tanaka, Y.; Okamoto, T. Space charge trapping in electrical potential well caused by permanent and induced dipoles for LDPE/MgO nanocomposite. IEEE Trans. Dielectr. Electr. Insul. 2008, 15, 152-160. [CrossRef]

38. Akmal, A.S.; Borsi, H.; Gockenbach, E.; Wasserberg, V.; Mohseni, H. Dielectric behavior of insulating liquids at very low frequency. IEEE Trans. Dielectr. Electr. Insul. 2006, 13, 532-538. [CrossRef]

39. Mu-zhen, S. Dielectric Physics; University of Technology Press: Guangzhou, China, 2000.

40. Richert, R.; Agapov, A.; Sokolov, A.P. Appearance of a Debye process at the conductivity relaxation frequency of a viscous liquid. J. Chem. Phys. 2011, 134, 104508. [CrossRef] [PubMed] 